\title{
Survey on COVID-19-related mortality associated with occupational infection during the first phase of the pandemic: A systematic review
}

\author{
PAOLA SENIA ${ }^{1}$, FRANCESCA VELLA ${ }^{1}$, NICOLA MUCCI ${ }^{2}$, GEORGE DOUNIAS ${ }^{3}$, ANTONIO TROVATO ${ }^{1}$, \\ ANDREA MARCONI $^{1}$, CATERINA LEDDA $^{1 *}$, VENERANDO RAPISARDA $^{1 *}$ and ERMANNO VITALE ${ }^{1}$ \\ ${ }^{1}$ Occupational Medicine, Department of Clinical and Experimental Medicine, University of Catania, I-95123 Catania; \\ ${ }^{2}$ Department of Experimental and Clinical Medicine, University of Florence, I-50139 Florence, Italy; \\ ${ }^{3}$ Department of Occupational \& Industrial Hygiene, National School of Public Health, 11521 Athens, Greece
}

Received November 2, 2020; Accepted June 2, 2021

DOI: $10.3892 /$ etm.2021.10932

\begin{abstract}
According to the Centre for Disease Control and Prevention in 2020, a cluster of pneumonia cases of unknown etiology caused by the severe acute respiratory syndrome (SARS)-coronavirus 2 was reported in Wuhan, China. The present review examined the literature to reveal the incidence of novel coronavirus-2019 disease (COVID-19) infections, underlying comorbidities, workplace infections and case fatality rates. A review was performed to identify the relevant publications available up to May 15, 2020. Since the early stages of the COVID-19 outbreak, the case fatality rate among healthcare workers (HCWs) has stood at $0.69 \%$ worldwide and $0.4 \%$ in Italy. Based on the current information, most patients have exhibited good prognoses in terms of after-effects or sequelae and low mortality rate. Patients that became critically ill were primarily in the elderly population or had chronic underlying diseases, including diabetes and hypertension. Among all working sectors, HCWs, since they are front-line caregivers for patients with COVID-19, are considered to be in the high-risk population. Increased age and a number of comorbidity factors have been associated with increased risk of mortality in patients with COVID-19. The most frequent complications of COVID-19 reported that can cause fatality in patients
\end{abstract}

Correspondence to: Professor Venerando Rapisarda or Dr Ermanno Vitale, Occupational Medicine, Department of Clinical and Experimental Medicine, University of Catania, Via Santa Sofia 87, I-95123 Catania, Italy

E-mail:vrapisarda@unict.it

E-mail: ermannovitale@gmail.com

*Contributed equally

Key words: novel coronavirus-2019 disease, mortality rate, comorbidity, health care workers, occupational exposure, current perspectives, severe acute respiratory syndrome were SARS, cardiac arrest, secondary infections and septic shock, in addition to acute kidney failure and liver failure. Overcoming the COVID-19 pandemic is an ongoing challenge, which poses a threat to global health that requires close surveillance and prompt diagnosis, in coordination with research efforts to understand this pathogen and develop effective countermeasures.

\section{Introduction}

Since the novel coronavirus-2019 disease (COVID-19) first emerged in Wuhan, China, it has rapidly spread to other areas of the country and then the world. It has now affected most countries in the world, with the epicenter having shifted from Asia to various parts of Europe and North America $(1,2)$. The virus that causes this disease was initially referred to as 2019-novel coronavirus (nCoV) by the Centre for Disease Control and Prevention (CDC), but was later given the name severe acute respiratory syndrome (SARS)-coronavirus 2 (CoV-2) (1).

The etiological agent of COVID-19, SARS-CoV-2, was identified on January 3, 2020 and was confirmed to belong to the genera of $\beta$-CoVs (3). Other viruses in the same family of CoVs have previously been identified to be the cause of SARS and Middle East Respiratory Syndrome (MERS) epidemics in 2003 and 2012, respectively $(4,5)$.

Soon after the identification of this virus, researchers worldwide began trying to discover the transmission pathways of this virus to humans, in addition to its pathogenicity and evolutionary origin, to ascertain the causes of mortality and the mechanism underlying severe cases of COVID-19 $(6,7)$. Human-to-human transmission was reported both in hospitals and family settings, which was found to be characterized by 2-10-day incubation times, and it was revealed to be spread through droplets in the air and contaminated hands or surfaces (5,8-10). Despite the adoption of extensive control measures worldwide, the impact of the COVID-19 pandemic has been devastating, with several categories of professions, particularly healthcare workers (HCWs), being among the worst hit (11). 
In past SARS and MERS CoV epidemics, HCWs were also markedly affected. During the SARS epidemic, HCWs represented $21 \%$ of all cases in the world (12). By contrast, in other countries, including Canada, Hong Kong and Singapore, that number reached $>50 \%$ of all cases, with multiple reported deaths (12). Recent data from Italy revealed that $11.9 \%$ of all diagnosed COVID-19 cases (27,439/230,414 diagnosed) occurred in HCWs (13). The infectivity of COVID-19 is greater than that of influenza $\left(\mathrm{R}_{0}\right.$ value, which the basic reproduction number, which represents viral infectivity, of 0.9-2.1), with an estimated $\mathrm{R}_{0}$ value of 2.28-3.10 $(14,15)$.

Despite intensive research efforts worldwide on the treatment of the SARS-CoV-2 infection, little is known regarding the causes of COVID-19-related mortality (16). The purpose of the present review was to analyze the causes of mortality associated with SARS-CoV-2 infection in general, with particular focus on the result of infection in a professional environment.

\section{Materials and methods}

PRISMA. This review was performed in accordance with the PRISMA statement (17).

Literature search. The SCOPUS (release date: September 26 2018; https://www.scopus.com), Medline (using PubMed as the search engine; Release date: January 1996; https://pubmed. ncbi.nlm.nih.gov/), Embase (version: 2020; https://www.elsevier.com/solutions/embase-biomedical-research) and Web of Sciences databases (version: 2020; https://www.webofknowledge.com) were searched to recognize the relevant literature available between January 1 and May 15, 2020, to examine the possible transmission pathways and causes of SARS-CoV-2 infection-related mortality.

The term 'MeSH' was used with the following entry terms: 'SARS-CoV-2' or '2019-nCoV' or 'Covid-19' or 'Wuhan coronavirus' or 'COVID19' and 'mortality' and 'HCWs', 'SARS-CoV-2' or '2019-nCoV' or 'Covid-19' or 'Wuhan coronavirus' or 'COVID19' and 'comorbidity' and/or 'HCWs'. Subsequently, a survey of the research manuscripts that were suitable for inclusion in this review was performed, and the research papers of importance therein were collected and reviewed.

Inclusion and exclusion criteria. The following inclusion criterion was adopted: Studies that investigated the causes of mortality as a result of SARS-CoV-2 infection. Research articles, clinical trial studies, reports from international agencies and case studies were included. No geographical restriction was applied. The following exclusion criteria were used: i) Scientific papers not published in English; ii) conference abstracts; iii) systematic reviews; and iv) meta-analyses. In cases of duplicate studies, the article with more detailed information was included.

Quality assessment and data extraction. A total of two external reviewers (CL and GD) retrieved the articles independently. The title, abstract and full text of each potentially relevant study were reviewed. Any disagreement on the eligibility of the studies was resolved by debate or by consulting the third reviewer (FV). The following information was extracted from all qualified papers: Authors, year of publication, nationality of subjects and study characteristics.

\section{Results}

Search results. Following a search of the scientific literature by the reviewers, a total of 978 documents were collected. A total of $260(26 \%)$ were excluded due to them being reviews, $596(61 \%)$ were excluded due to them being only abstracts and $45(5 \%)$ studies were disqualified after a subsequent review of the title. A total of $64(7 \%)$ of the papers were ruled out due to not being written in English. At conclusion, 13 (1\%) studies complied with the inclusion criteria and were included in the present review (Fig. 1) (18-30). The data mainly came from studies in Chinese and Italian populations, since China and Italy were among the first countries affected during the first pandemic phase.

Epidemiological analysis of mortality data. Since the early stages of the COVID-19 outbreak, in February, 2020, the case fatality rate (CFR; defined as the ratio resulting from the number of individuals deceased divided by the number of total recorded infections) in China has been 2-4\% (14). This is a much lower CFR compared with that of SARS and MERS, which were $\sim 10$ and $\sim 35 \%$, respectively, but higher than that of influenza $(0.1 \%)(4,31)$.

The COVID-19 pandemic is rapidly developing. At the time of writing the present review (June 2020), it has been $\sim 6$ months since the first case of COVID-19 was reported in Wuhan. So far, according to a report from the World Health Organization, COVID-19 has affected 4.5 million individuals worldwide, with 302,462 deaths as of May 15, 2020. Italy ranked fourth in the world in terms of case number and second in terms of mortality during the first 3 months of pandemic (16). By May 15, 2020, Italy's CFR was $\sim 13 \%$, whilst that in China was only $4 \%(32,33)$. Such a high figure is typified by the observations in the Lombardy region, where $\sim 50 \%$ of all Italian infections have been recorded, with the CFR there being $\sim 16 \%$ (31). However, it should be noted that CFR is generally an overestimated value of actual lethality, which is measured as the infection fatality ratio (IFR). In addition, the real number of cases of infection, including asymptomatic and paucisymptomatic cases, are likely underestimated due to them being easily overlooked as a result of limited testing (34). IFR is the parameter that measures the percentage of reduction over the overall infected population, including the generally unknown number of recorded cases that were not recorded (34).

Tables I-III show the main results of the eligible studies (18-30). Based on this information, most patients with COVID-19 had good prognoses, whilst a few were in a critical condition, particularly the elderly and those with chronic underlying diseases (9). Statistical analyses performed worldwide have confirmed that SARS-CoV-2 infection affects men and women differently $(9,18-21,23-26,28,29,32,35)$. The fatality rate of confirmed cases in China is $4.7 \%$ in men, compared with $2.8 \%$ in women (35). These data are relevant with regards to $\mathrm{HCWs}$, which are mainly represented by women (90\%) in the Hubei province in China (35). Therefore, any interpretation of the differences in sex among age 


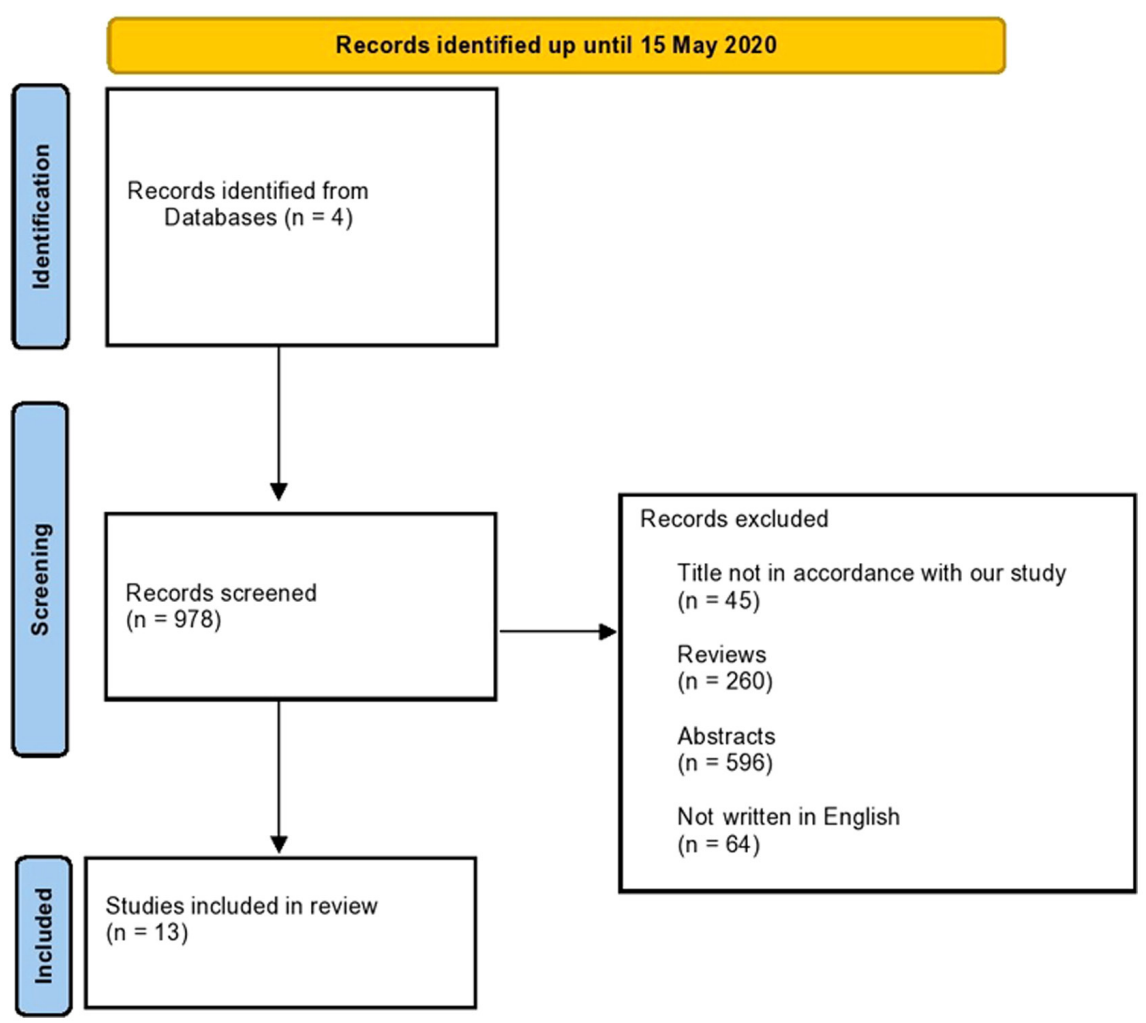

Figure 1. Flow diagram illustrating the included and excluded studies in this review.

groups and countries must be made with great caution (32). Italian data also supported this trend (18); the latest analysis conducted by the Italian National Institute of Health (ISS) on a population of 18,641 patients (deceased and tested positive for SARS-CoV-2) in Italy revealed that 6,339 patients were women (34\% of the total), and of those who died after being infected with SARS-CoV-2, the women were generally older compared with the corresponding group of men who succumbed to COVID-19 (mean age in women, 83 years; mean age in men, 79 years) (18). To explain this, a number of general hypotheses were made, including the following: i) Stronger smoking habits among men; ii) higher attention to daily personal hygiene among women; iii) more effective innate and adaptive immune responses in women (36). In addition, differences between men and women with regard to mechanisms of infection, which can be associated with differences in hormonal and genetic profiles, were also highlighted $(37,38)$.

Advancing age, hypertension, high lactate dehydrogenase levels, as well as men with severe heart trauma, hyperglycemia and use of high-dose corticosteroids were previously associated with a higher risk of mortality in general $(39,40)$. Patients with cardiovascular disease (CVD) who were infected with the virus were also associated with an elevated risk of adverse outcomes, such that the infection itself was found to be associated with CVD complications (41-43).

Infection caused by or occurring in the workplace and mortality. Following a review of the literature, only studies that analyzed the relationship between infection and mortality in HCWs could be found. To the best of our knowledge, no other working sector appears to have been investigated in depth. Of the several professional scenarios where individuals could be exposed to SARS-CoV-2, only environments of HCWs appeared to be associated with the highest risk of exposure (44-48).

As front-line caregivers for patients with COVID-19, HCWs are considered to be in the high-risk population (49). Medical staff caring for these patients face mental stress, physical exhaustion, separation from families, stigma, and the emotional stress of losing their patients and colleagues $(50,51)$. Multiple HCWs have acquired SARS-CoV-2 and some have died. In Italy, as of May 2020, 203 HCWs had succumbed to COVID-19 (33).

As of February 11, 2020, 3,019 HCWs were reported to have been infected with SARS-CoV-2 in China. A total of $1,716 \mathrm{HCW}$ cases were confirmed by nucleic acid testing (52) and $\geq 6$ HCWs have died (28). It was estimated that $3.8 \%$ patients with COVID-19 were HCWs as reported by Zeng Yixin, vice minister of China's National Health Commission during a news conference, on February 14th, 2020 (53). In addition, hospital-associated transmission has been reported to be a major route of spreading SARS-CoV-2 (2).

HCWs are frequently at higher risks of being infected during novel disease outbreaks, particularly before the transmission dynamics have been fully ascertained $(48,54,55)$. Risks of SARS-CoV-2 infection may be higher among professionals who work closely with patients, including dentists and ophthalmologists $(56,57)$. In addition, certain procedures, such as non-invasive ventilation, high-flow nasal cannula and bag-mask ventilation, are key treatments performed in non-mechanical ventilation wards that may generate large volumes of aerosol (58). HCW infection risks can be lessened if proper precautions are taken in hospitals, such as using personal protective equipment (PPE) $(47,48,54,59,60)$. 


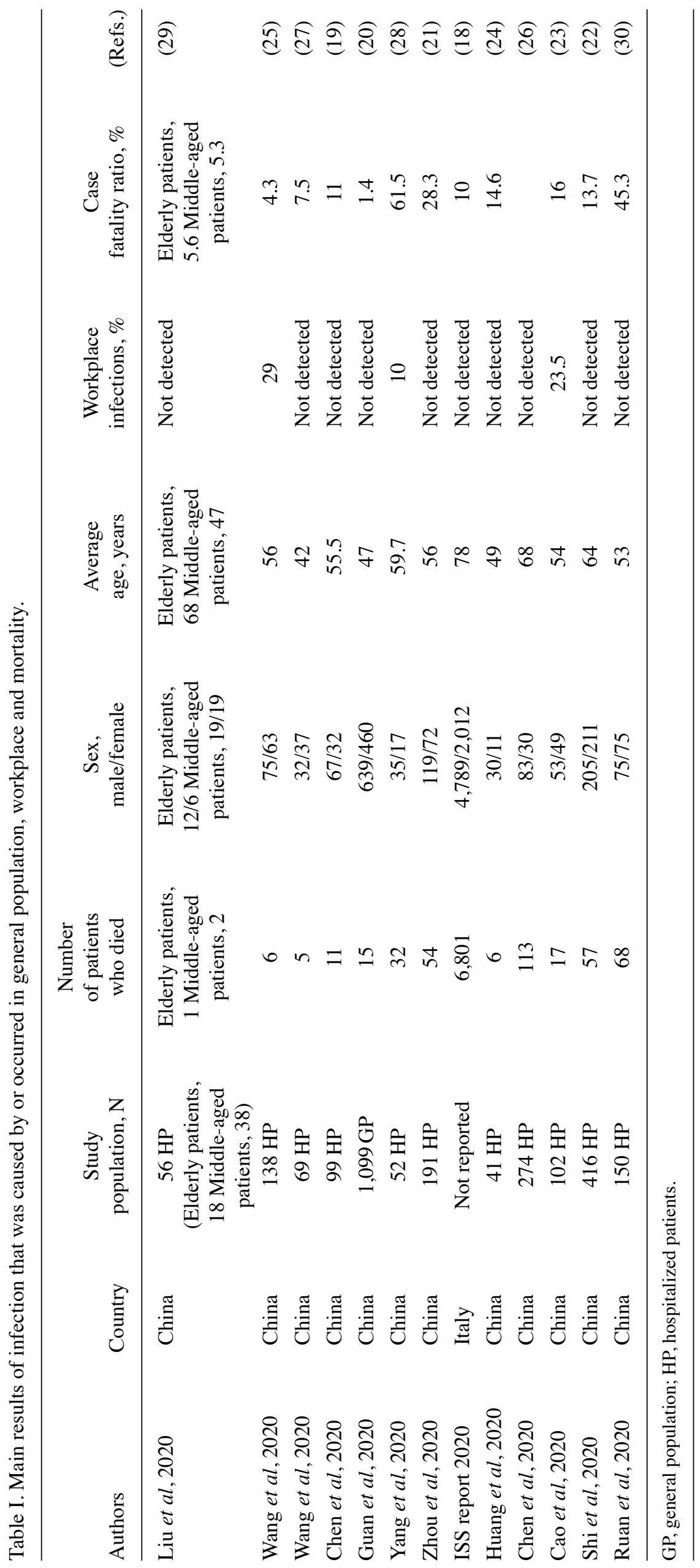




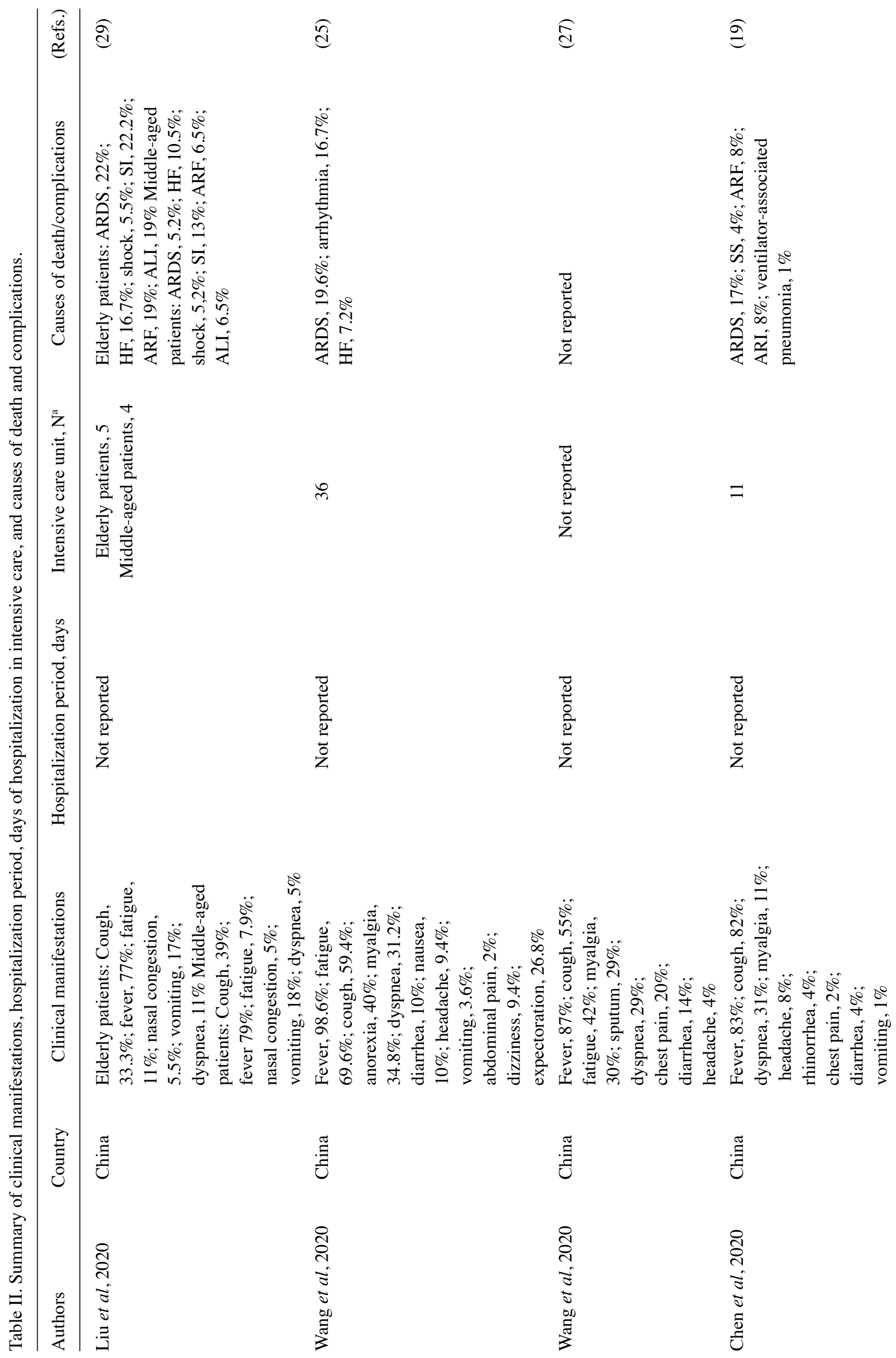




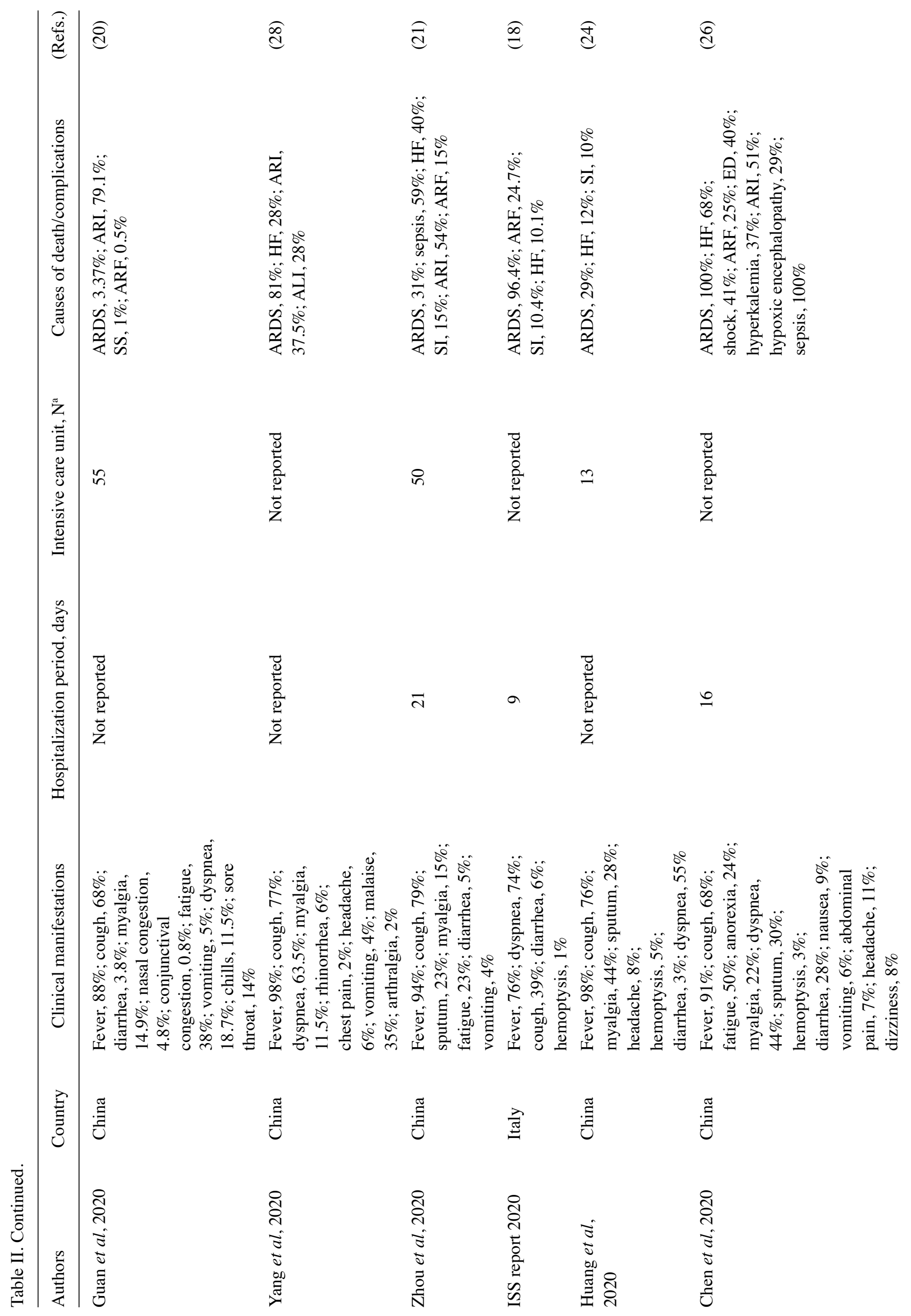




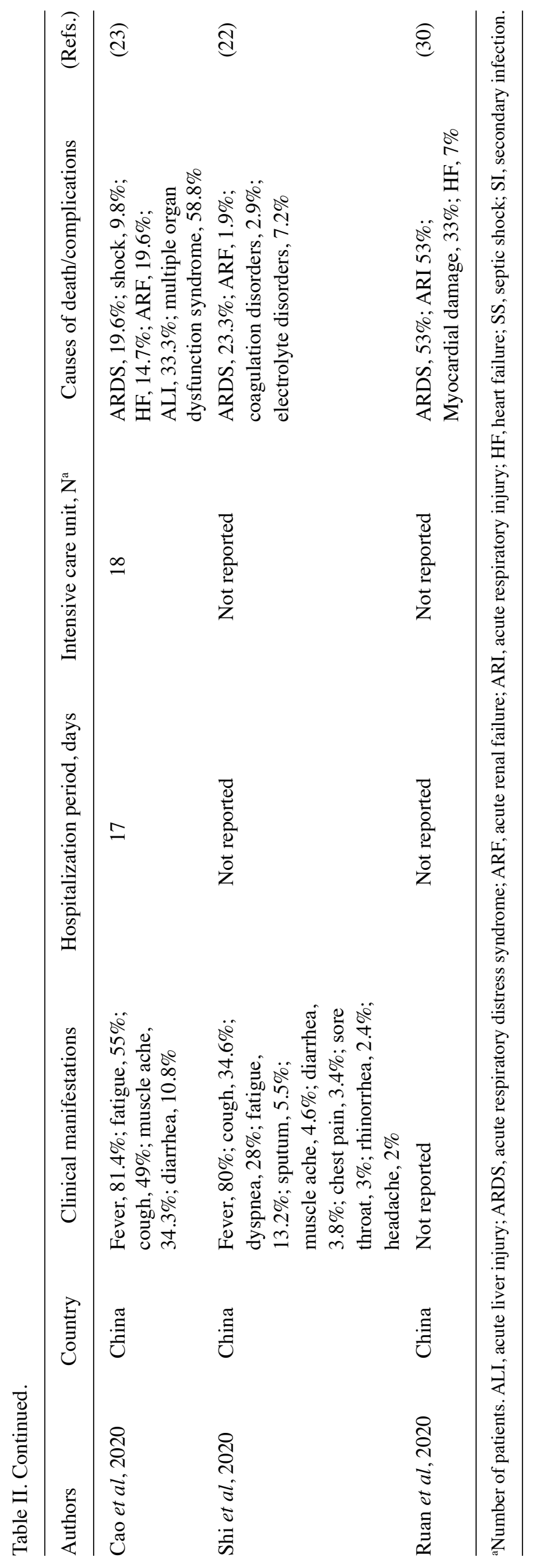




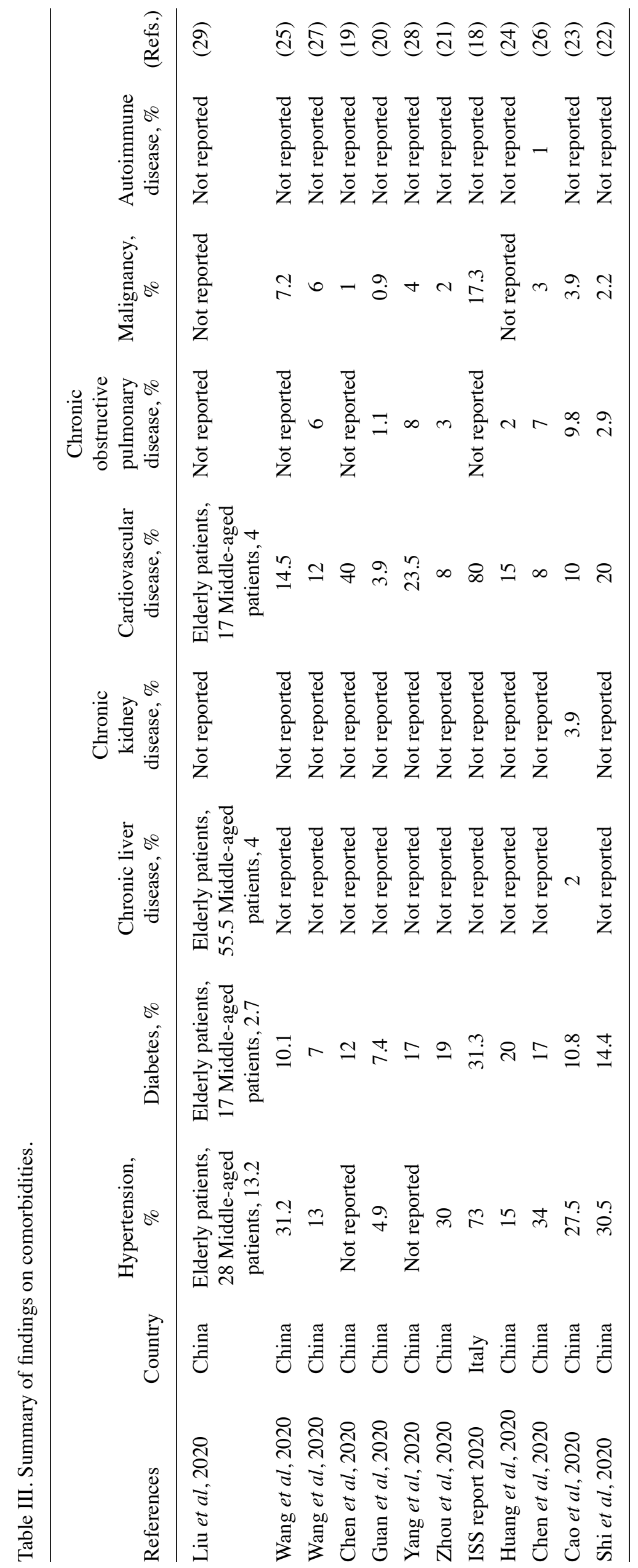


To date, little is known regarding the route of SARS-CoV-2 transmission in healthcare milieus. Heinzerling et al (55) previously described the first known cases of occupational SARS-CoV-2 transmission to HCWs in Solano Hospital (Solano County, CA, USA). Among a cohort of 121 healthy HCWs who were exposed to patients COVID-19 positive without protection, 43 of whom were symptomatic, but only three developed confirmed COVID-19 despite multiple protected exposures (55). HCWs who developed COVID-19 had a longer duration of exposure to the patient than other HCWs, whose origin of SARS-CoV-2 infection was initially unknown (55). In addition, exposure during nebulizer treatments and biphasic positive airway pressure was also more common among HCWs who developed COVID-19 (55). These results emphasize the increased COVID-19 transmission risk associated with prolonged, unprotected patient contact and the importance of ensuring that HCWs exposed to patients with confirmed/suspected COVID-19 are well protected (50).

With regards to the USA, there is no comprehensive analyses of mortality among HCWs. During March 1-May 31,2020 , COVID-NET in the USA received reports of 28,972 hospitalized adult patients. HCP status was documented for 6,760 of the sampled patients, 438 of whom were HCPs, yielding a weighted estimate of $5.9 \%$ (95\% $\mathrm{CI}=5.1-6.8 \%)$. A substantial proportion of HCP with COVID-19 had indicators of severe disease: $27.5 \%$ were admitted to an intensive care unit (ICU), $15.8 \%$ required invasive mechanical ventilation and $4.2 \%$ died during hospitalization (61). This value included doctors, nurses and paramedics, in addition to important healthcare support staff, including hospital janitors, nursing home workers and administrators (61).

In Italy, according to the National Institute for Insurance against Accidents at Work data (updated to include data up to May 15,2020$), 43,399$ reports associated with COVID-19 infection were made, $54 \%$ of which occurred in March and very quickly spread to Northwest Italy (62). Of these 43,399 COVID-19 reports, almost all (99\%) were associated with industry and services' insurance management, with cases recorded in other sectors including agriculture, navigation and state administration ( $<500$ cases) (62). Of those reports, $72.8 \%$ were from the healthcare and social services sectors, including hospitals, private clinics and assisted health centers, compared with those in productive activities, such as the food supply chain, involved in the pandemic (62).

With regards to lethal exitus in HCWs, a survey (data available up to May 15, 2020) included 171 reports of deaths for COVID-19, where $82.5 \%(\mathrm{n}=141)$ of these were men and $17.5 \%(n=30)$ were women (62). The mean age of these patients was 59 years (for both sexes). The age range data showed that $79.8 \%(n=121)$ of the overall cases of COVID-19 were patients aged 50-64 years. The $>64$-year age group was next at $19.3 \%$ $(n=33)$, then the 35-49-year age group at $8.2 \%(n=14)$ and finally the $<34$-year age group at $1.7 \%(n=3)(50)$.

A previous territorial analysis revealed the following distribution of mortality in Italy: $57.9 \%(n=99)$ occurred in northwest Italy (Lombardy 43.9\%), 14.0\% $(\mathrm{n}=24)$ in northeast Italy (Emilia-Romagna, 8.2\%), 11.1\% $(\mathrm{n}=19)$ in central Italy (Marche, 4.1\%), 15.2\% $(\mathrm{n}=26)$ in southern Italy (Campania, $7,6 \%)(n=9)$ and $1.8 \%(n=3)$ in the Italian island of Sicily $(62)$ In detail, HCWs as healthcare technicians $(70 \%$ of whom are nurses) and physicians were the most at risk of virus infection, where $15.5 \%$ of cases were codified, followed by healthcare social workers (10.7\%), administration employees $(8.3 \%)$ and social services workers $(6.0 \%)(62)$.

Clinical manifestations. The complete clinical manifestation of COVID-19 infection includes respiratory, neurological, cardiovascular and coagulative symptoms, which in certain cases can result in mortality (Table II) (18-30,63-68).

The most common symptoms reported in the articles examined in the current review were as follows: Fever (76-98.6\%), cough (34.6-82\%), myalgia or weakness (11-44\%), pneumonia and complicated dyspnea (5-74\%; Table II) (18-21,24-30,69). Less commonly reported symptoms included headache, diarrhea (3-28\%), hemoptysis, sore throat (3-14\%), rhinorrhea (2.4-6\%) and phlegm-producing cough (Table II) $(18-21,24-30,68)$. In addition, patients with COVID-19 tended to show higher leukocyte numbers, prolonged prothrombin time (24), abnormal respiratory findings and increased levels of plasma proinflammatory cytokines, including IL-1, IL-6 and TNF (Table II) (70).

According to several studies, significantly higher blood levels of cytokines and chemokines were found in patients with COVID-19, including interleukin (IL)-1 $\beta$, IL-1RA, IL-6, IL-7, IL-8, IL-9, IL-10, colony-stimulating factor (CSF), fibroblast growth factor-2, granulocyte-macrophage $\mathrm{CSF}$, monocyte chemoattractant protein 1 (MCP1), IFN- $\gamma$, macrophage inflammatory protein $1 \alpha$ (MIP1 $\alpha)$, MIP1 $\beta$, platelet-derived growth factor subunit $\mathrm{B}, \mathrm{TNF} \alpha$ and vascular endothelial growth factor $(23,25)$. Some of the patients with severe COVID-19 who were admitted to the ICU exhibited high levels of proinflammatory cytokines, including IL-2, IL-7, IL-10, granulocyte-CSF, C-X-C motif chemokine ligand $1, \mathrm{MCP} 1, \mathrm{MIP} 1 \alpha$ and TNF $\alpha$, all of which are considered to enhance disease severity $(71,72)$.

High erythrocyte sedimentation rate and D-dimer levels have also been detected (73). The main manifestations of severe COVID-19 in the respiratory system were severe pneumonia and detectable serum SARS-CoV-2 viral load, combined with the incidence of ground-glass opacity in the lung and acute cardiac injury (ACI) (24).

Bonetti et al (74) previously reported that several laboratory abnormalities, including lymphopenia, increased values of $\mathrm{C}$ reactive protein, lactate dehydrogenase, erythrocyte sedimentation rate, accurately predicted the risk of mortality in a cohort of 144 patients with COVID-19. A number of studies suggested that a marked decrease in the total number of lymphocytes indicated that SARS-CoV-2 can destroy immune cells to inhibit immune function $(74,75)$. Furthermore, damage to $\mathrm{T}$ lymphocytes may be one of the important factors leading to disease exacerbation in patients with COVID-19 $(70,71)$. The low absolute lymphocyte value could be used as a referencing index for the clinical diagnosis of new SARS-CoV-2 infections (75).

Comorbidities. Old age, obesity and smoking habits (76) may be associated with increased mortality (Table III) (19). Populations with reduced immune functions, including the elderly, patients with diabetes and HIV, in addition to individuals with long-term use of immunosuppressive drugs, are 
associated with increased risk of complications and higher mortality rates in COVID-19 (Table III) (19). For example, patients with diabetes are at higher risks of ketoacidosis during COVID-19, whereas patients with chronic kidney disease frequently develop renal dysfunction that necessitates kidney transplantation (20). Therefore, clinicians need to thoroughly assess the comorbidities of patients on an individual basis during diagnosis and the treatment of COVID-19 (77).

Similar to patients that were affected by avian origin influenza A, elderly men suffering from comorbidities and acute respiratory distress syndrome (ARDS) have been reported to have a higher mortality risk (75). In all of the studies analyzed (Table II), ARDS was reported as a major cause of mortality. Fig. 2 summarizes the main comorbidities of COVID-19, including hypertension, COPD, cardiovascular disease, diabetes and malignancies and outcomes in patients who died of COVID-19, including ARDS, acute respiratory injury and heart failure.

Patients with CVD have a greater risk of COVID-19. Previous studies have revealed an association between CVD and SARS or MERS in terms of disease severity and the risk of death $(76,77)$. In addition, a large number of studies have reported an association between pre-existing CVDs and the severity of COVID-19 (10,18,19,21-27,76-80).

A systematic analysis of 637 MERS-CoV cases showed that hypertension and diabetes were prevalent in $~ 50 \%$ of patients, whereas CVDs were present in 30\% of cases (29). Diabetes was also identified as an independent predictor of mortality and morbidity in patients with SARS (72). A total of 12 studies (18-29) reported diabetes among the comorbidities of patients who succumbed to COVID-19, whilst 10 studies $(18,20-27,29)$ previously reported hypertension as a risk factor (Table III).

With the spread of SARS-CoV-2 and the increase in cases, an increasing number of infected individuals have exhibited comorbidities such as diabetes, hypertension and CVD (41). Chen et al (19) previously reported a higher number of men with SARS-CoV-2 infection compared with women. The reduced susceptibility of women to all viral infections may account for the important role of the $\mathrm{X}$ chromosome and sex hormones in innate and adaptive immunity $(19,81)$.

Hospitalization period. According to the Italian Report of ISS published on March 26, 2020, among the Italian patients who succumbed to COVID-19, the median hospitalization time from symptom onset to death was 9 days; 4 days from symptom onset to hospitalization and 5 days from hospitalization to death. The time from hospitalization to death was 2 days more in those who were moved to ICU compared with those who were not (6 vs. 4 days) (82). According to Chen et al (19), in deceased patients, the median time from symptom onset to hospitalization was 10.0 days (interquartile range, 7.0-13.0), which tended to be longer compared with that in patients who recovered [9.0 (6.0-12.0) days]. The median time from symptom onset to death was 16 (12.0-20.0) days, whereas the median time from symptom onset to discharge for patients who recovered was 26 (21.8-29.0) days. The median time from hospitalization to death was 5 (3.0-9.3) days and the median time from hospitalization to discharge was 16 (14.0-19.0) days (65). According to a study by Cao et al (23), the median time from symptom onset and from SARS-CoV-2 exposure to death was 15 and 17 days, respectively.

Causes of mortality. All studies examined in the present review (Table II) reported ARDS (18-26,28-30) and acute respiratory injury (ARI) $(19-21,26,28,30)$ as the main COVID-19-related complications followed by cardiac complications, including arrhythmia, heart failure and myocardial damage (Fig. 2) (18,21,23-26,29-30).

The high prevalence of arrhythmia may be partly caused by metabolic dysfunction, hypoxia, neurohormonal or inflammatory stress as a result of viral infection in patients with or without prior CVD $(28,83)$. Zou et al (8) reported that heart failure was observed in $23 \%$ of patients with COVID-19 presentations. In particular, heart failure was more commonly detected than acute renal failure (ARF) in this cohort and was more common in patients who did not survive hospitalization than in those who did (18-21,26,29). With regard to ARDS, respiratory failure is characterized by the rapid onset of widespread lung inflammation and subsequent mortality $(18,21,24,25)$. The mortality rate of ARDS in all patients with COVID-19 was $~ 50 \%$ and if ARDS reached the moderate/advanced stages, the mortality rate reached as high as $70 \%(19,29)$.

Cardiovascular event risk factors following pneumonia include old age, pre-existing CVD and severe pneumonia at admission (84). Coronary heart disease has also been found to be associated with poorer outcomes in influenza and other viral respiratory infections (84).

Other common complications associated with COVID-19 include shock (64), ARF, acute liver injury (ALI) and secondary infection $(23,24,28,29)$. Multiple organ dysfunction syndrome can either occur individually at different times or concurrently $(23,25,79)$. Secondary infection, sepsis and subsequent septic shock have been reported by seven previous studies (18-21,24,26,29). According to Zhou et al (21), sepsis developed at a mean of 9 days after illness onset in all patients with COVID-19. Coagulopathy commonly occurs during sepsis and may be an indicator of worse outcomes of severe COVID-19 (20). ARI and systemic coagulopathy can be listed as two of the underlying causes of morbidity and mortality that characterize SARS-CoV-2 infection (85).

Recent observations have suggested that respiratory failure during COVID-19 is not followed by the development of ARDS alone and that microvascular thrombotic processes may also serve a role (86). These processes may have significant consequences as far as the diagnostic and therapeutic management of these patients is concerned. A strong association has been found among the D-dimer levels, disease progression and chest CT features, suggesting venous thrombosis (21). Han et al (87) previously reported reduced coagulation functions in patients with SARS-CoV-2 infection compared with those in healthy individuals, including elevated D-dimer, fibrin/fibrinogen degradation products and fibrinogen levels. In addition, Zhou et al (21) and Tang et al (88) recently reported a positive correlation between elevated D-dimer levels upon hospitalization and in-hospital COVID-19 mortality, suggesting the presence of an unknown pulmonary embolism and the possible role of CT pulmonary angiography in the rapid identification of cases that will undergo rapid clinical deterioration with COVID-19. 


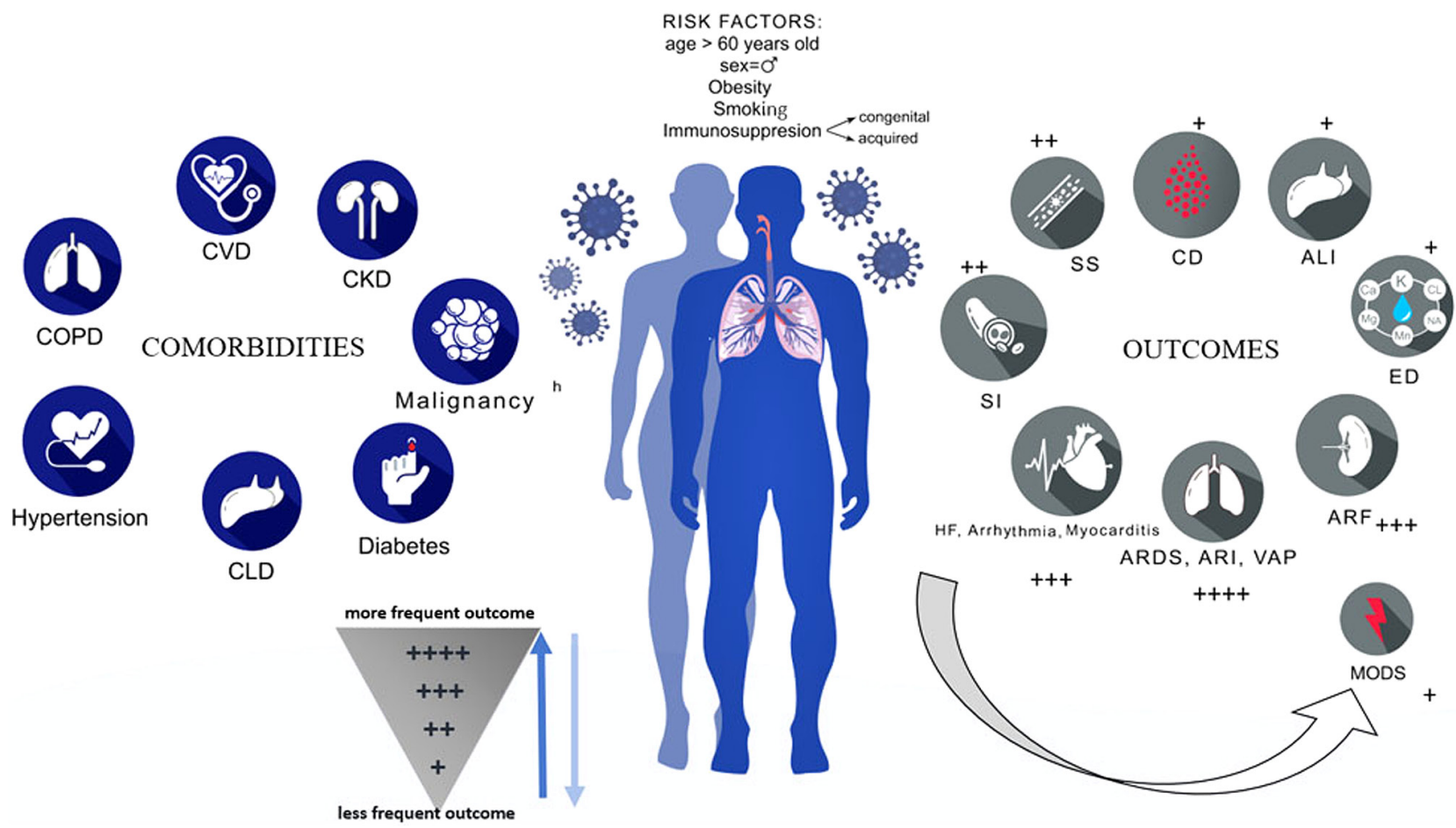

Figure 2. Comorbidities and outcomes of patients who succumbed to COVID-19. ALI, acute liver injury; ARDS, acute respiratory distress syndrome; ARF, acute renal failure; ARI, acute respiratory injury; CD, coagulation disorders; CLD, chronic liver disease; CKD, chronic kidney disease; COPD, chronic obstructive pulmonary disease; CVD, cardiovascular disease; ED, electrolyte disorders; HF, heart failure; MODS, multiple organ dysfunction syndrome; SI, secondary infection; SS, septic shock; VAP, ventilator-associated pneumonia.

ARF was previously assessed as a complication in five different studies and was found to have a higher incidence rate in Italy compared with that elsewhere, where it was detected in $24 \%$ of deceased patients $(18,20,21,26,29)$. In addition, ARF was revealed to be more common among patients with more severe disease, particularly those admitted to the ICU and could therefore be considered a negative prognostic factor of survival (89).

It has been suggested that an insufficient systemic inflammatory immune response during a cytokine storm may contribute to the hypoperfusion-related damage of renal tubules (90). In addition to organ dysfunction as a result of immune dysregulation, emerging evidence has suggested the possibility of a direct cytopathic effect of SARS-CoV-2 (91).

ALI as a COVID-19 complication was observed only by three studies $(23,28,29)$. In the study by Yang et al $(28)$, which detected in $28 \%(\mathrm{n}=14)$ of the examined patients, all of whom were admitted to hospital already in a critical condition.

It was observed in some studies that poorer clinical outcomes were associated with disease severity $(29,29,63,67)$. In addition, disease tended to progress faster in the elderly, with a shorter median number of days from early symptom onset to death recorded among people aged $\geq 65$ years (67).

Cytokine release syndrome (CRS) is a systemic inflammatory response that occurs in a large number of patients with severe COVID-19, which is also an important cause of death (92). IL-6 is the key molecule of CRS (92). SARS-CoV-2 binds to alveolar epithelial cells and then activates innate and adaptive immune systems, resulting in the release of a large number of cytokines, including IL-6 (93). During the first phase of the pandemic, the therapeutic use of an IL-6 receptor antagonist (tocilizumab) in combination with corticosteroids was recommended for the treatment of cytokine storm, which reduced the dose and treatment period compared with corticosteroid therapy alone (94). However, after the studies were conducted, its use was eliminated since it showed no clinical benefit (95-97). Given the proposed role of these proinflammatory factors, increases in vascular permeability can let a large amount of fluid and blood cells into the alveoli, resulting in dyspnea and even respiratory failure $(98,99)$. The first gross examination report of an autopsy of a patient who succumbed to COVID-19 revealed that the bronzed aspect of both lungs and a large amount of gray-white viscous liquid overflow could be observed following incision (100).

\section{Discussion}

COVID-19-related contagion and mortality rates are continuously growing worldwide, having spread from China to the rest of the world, including South America (64). During the initial stages of the pandemic, Italy, Spain and France were particularly affected in Europe $(101,102)$. As of May 2020, the USA is the country with the most COVID-19 cases $(>1,361,522$ cases) (102) and a 6\% mortality rate. By contrast, the mortality rate in Italy is $13 \%$ (103). Latin America and the Caribbean are also witnessing increasing infection rates, with $>425,000$ cases (102). In addition, Brazil, Peru, Chile and Mexico are countries that are on the list of the highest numbers of infections in the Americas (102). In Brazil, the pandemic was growing exponentially with an increase of 10,000 infections per day as of May 2020 May (104). 
COVID-19 was also analyzed as an outcome of infection in the workplace. The analyzed data revealed that healthcare and social services have been particularly affected (105). In the USA, HCWs represent 10-20\% of patients with COVID-19, a number similar to that observed in other badly affected countries, such as Italy and Spain (103). In Italy, 17,000 HCWs have been infected at the time of writing (May 2020) (106). Although a number of studies have explored COVID-19 in HCWs worldwide $(23,50,62,107)$, to date, systematized mortality data are scarce (49).

The high number of infections among HCWs, mainly during the early stages of the outbreak, could be attributed to a lack of awareness regarding its presence in hospitals treating patients with SARS-CoV-2 infection $(54,108)$. In addition, only a partial knowledge of the risks, lack of bespoke preventive actions and possibly the inadequate availability of PPE have been proposed to serve a role in the number of infections $(54,108)$.

The Italian healthcare system is a well-developed healthcare system (109); however, the country was unprepared to cope with the impact of COVID-19 (110). According to Chou et al (110), a significant diffusion route of SARS-CoV-2 is in-hospital transmission, particularly through HCWs. This was largely underestimated at the early stages of the pandemic, including by the HCWs themselves $(49,111)$.

In some hospitals in Europe, especially in Italy and Spain, the same waiting rooms contained both patients who were infected and those who were not (112). This provided a favorable milieu for the virus to spread (111). Incidentally, centralized ventilation systems also made a negative contribution, since they did not contain high-efficiency particulate air filters, which may have functioned to trap the viral particles (93).

The guidelines developed during the first pandemic phase for the prevention of SARS-CoV-2 infection recommend the use of rapid diagnostic tests for the screening of patients and HCWs prior to their admission to hospital, which has enabled the early identification of asymptomatic cases $(102,105)$. The currently available molecular diagnostic methods have also improved. In addition, antibody-based methods used to detect infections that went undetected in the population, including those that are asymptomatic, were also employed early but were found to be unsuitable for early disease detection (59,113-115). Furthermore, according to Li et al (112), HCWs were not well-prepared for this sudden COVID-19 outbreak, particularly in departments of infectious diseases.

During the first phase of the pandemic, little was known regarding SARS-CoV-2 transmission in the health care sector. Reports from Singapore, Illinois, USA and Hong Kong previously described clusters of HCWs exposed to patients with COVID-19 without any documented HCW transmission $(116,117)$. Most cases of HCW exposure to COVID-19 occurred even when the HCWs were using precautions against contact, droplet or airborne risks (93). In addition, as COVID-19 community transmission increased, determining whether HCW infections develop in workplaces or in the general population became increasingly difficult (50).

The studies examined in the present review confirmed that increased age was associated with increased risk of mortality in patients with COVID-19 (18-30). Although the mean age of patients tested positive for SARS-CoV-2 observed in China was lower than that in Italy, mean life duration should be taken into consideration, as it is longer in Italy compared with China (40,52).

According to Zhou et al (21), age-related defects in T- and B-cell function, in addition to the excess production of type 2 cytokines, may lead to the insufficient control of viral replication and more prolonged proinflammatory reactions. This can potentially result in poorer outcomes. Cardiac complications, including the induction or aggravation of heart failure, arrhythmia and myocardial infarction are common among patients with pneumonia (21).

Cardiac arrest was observed in $\sim 3 \%$ of patients with pneumonia (117). Cardiovascular event risk factors following pneumonia include old age, pre-existing CVD and high severity of pneumonia at admission $(21,116)$. Most deceased patients in all studies had at least one comorbidity $(18,20,21,22,24-28,30)$. The most common pre-existing pathologies diagnosed prior to infection with COVID-19 were hypertension, diabetes, ischemic cardiopathy, atrial fibrillation and active cancer in the last 5 years $(18,23,24,64,66-68,78,79)$. Furthermore, the main complications causing lethal exitus in patients were ARDS with ARI, cardiac failure, secondary infection and septic shock, with ARF and ALI only appearing in a small percentage of cases $(18,20-22,24,27,28,30)$.

According to Liu et al (29), admission to the ICU with mechanical and assisted ventilation was only required for elderly patients. Furthermore, in a study performed by Huang et al (24), patients admitted in ICUs had higher plasma levels of proinflammatory cytokines, such as IL-2, IL-7, IL-10 and TNF $\alpha$, compared with patients not admitted to the ICU. The highest mortality rate was recorded in ICU cases (24).

According to Chen et al (19), patients with COVID-19 may also be at risk of severe lung embolism. According to Magro et al (85), severe COVID-19 may define a type of microvascular damage syndrome mediated by the activation of complement pathways and an associated pro-coagulant condition.

Although both the etiology and incidence of acute pulmonary embolism under the setting of COVID-19 pneumonia remain unclear, available biological and clinical data raised concerns regarding unsuspected pulmonary embolism and warrants further research into this specific issue (117). The International Society on Thrombosis and Haemostasis advocates the use of laboratory tests, including tests for D-dimers, prothrombin time and platelet count, to identify patients who are at risk of an adverse outcome and require hospitalization (118).

According to the ISS report that described the characteristics of 6,801 patients with COVID-19 who died in Italy, the mean patient age at death was 78 years, with women comprising $29.6 \%$ of all deaths and being older than men at the time of death. The majority of patients with the infection died of ARDS, followed by ARF, secondary infections and ALI (18). This potentially explains why the median age of deceased Italian patients is much older than that of patients in other countries, and may also contribute to the increase in the mortality rate to $\leq 13 \%$ (119). Elderly age is associated with the presence of comorbidities that can contribute to the mortality of patients with COVID-19 $(18,119)$. However, these mortality rate estimates are based on the number of casualties relative 
to the number of confirmed cases of infection and do not represent the actual death rate. Patients who die on any given day were infected much earlier and therefore the mortality rate denominator should be the overall number of individuals infected at the same time as those who died (120). However, the full denominator remains unknown since asymptomatic cases or patients with mild symptoms may not be tested and will not be confirmed as COVID-19 cases. Such cases therefore cannot be included in the assessment of real mortality rates as actual estimates only pertain to clinically apparent COVID-19 cases. These findings showed that the current numbers may be underestimating the potential threat of COVID-19 in symptomatic patients (120).

During the first pandemic phase in the world, no autopsies have been performed on any patients who succumbed to COVID-19. Therefore, in most cases, there was no official verification of the causes of death (121), which has led to the loss of information regarding the causes that resulted in lethal exitus that could have provided useful information for treatment strategies (122).

Due to the potential infection by SARS-CoV-2, tight control is essential to monitor its potential host adaptation, infectivity, viral evolution, transmissibility and pathogenicity, to obtain an effective vaccine and accelerate herd immunity $(90,123,124)$.

Despite the short time elapsed since the COVID-19 outbreak, a large number of studies have been conducted and large quantities of real-time information have been generated. This enabled the present review to provide an accurate description of the mortality causes. A limitation of the present study is that it only focused on articles published in English during the early stages of the outbreak, considering that this pandemic was initiated in China. Although the data examined herein cannot be used to represent the rest of the world in terms of COVID-19, it will provide a foundation for further studies. Furthermore, in the present study, the COVID-19-related mortality due to occupational infection was only described during the first phase of the pandemic. Therefore, no second-wave mortality data were reported. The existing data on COVID-19-mediated mortality were mainly centered on China and Italy, but not on other European countries. Since COVID-19 case numbers have rapidly increased, particularly in European countries, it is of importance to determine the transmissibility and mortality rates of SARS-CoV-2 in these countries to establish prevention and control procedures. Lastly, the analysis of COVID-19 in the present study was also performed with regards to mortality in HCWs. However, analysis on the incidence, mode of transmission and clinical characteristics would have been difficult due to incomplete data.

Following a thorough analysis of the studies in the present review, it may be reasonable to question whether COVID-19 should be categorized as severe pneumonia. According to Pomara et al (16), the only medical method that can address this issue is autopsy. Despite the decline in the frequency of postmortem examinations, autopsies are a useful procedure for determining the cause of deaths. Physicians are now considering whether COVID-19 has a systemic pathology that involves the vascular system of other body regions instead of only the lungs, including the heart, kidneys, liver, bowels, brain or even the skin $(24,117,125)$. Pomara et al (16) strongly recommended conducting total autopsies on patients who succumbed to suspected or confirmed COVID-19, particularly in the presence of other comorbidities.

COVID-19 is a public health and humanitarian crisis that has put the healthcare systems of numerous countries under pressure and has caused the death of thousands worldwide, including hundreds of HCWs engaged in the frontline care of patients (126). Additional studies are required to further clarify the pathophysiology of COVID-19, which appears to be more of a multi-organ disease than a type of pneumonia. In any case, the presence of comorbidities definitely remains a prognostic factor for predicting an unfavorable outcome.

In conclusion, the COVID-19 pandemic is an ongoing challenge and poses a threat to global health. Therefore, control over the spread of the virus, fast diagnostics and research efforts are required to understand this pathogen and develop effective countermeasures.

\section{Acknowledgements}

Not applicable.

\section{Funding}

No funding was received.

\section{Availability of data and materials}

Not applicable.

\section{Authors' contributions}

PS, FV and EV prepared and drafted the manuscript. PS, VR, AT, GD and CL conceived and designed the study. PS, EV and VR performed the literature search and analysis. GD, NM, $\mathrm{AM}$ and AT reviewed and edited the manuscript. NM, EV, CL and VR supervised and revised the manuscript. All authors read and approved the final manuscript.

\section{Ethics approval and consent to participate}

Not applicable.

\section{Patient consent for publication}

Not applicable.

\section{Competing interests}

The authors declare that they have no competing interests.

\section{References}

1. World Health Organization. Coronavirus disease (COVID-19) pandemic. Novel Coronavirus (2019-nCoV). Available from: https://www.who.int/emergencies/diseases/novel-coronavirus-2019. Accessed February 7, 2020

2. World Health Organization. WHO Director-General's opening remarks at the media briefing on COVID-19-11 March 2020. Available from: https://www.who.int/dg/speeches/detail/ who-director-general-s-opening-remarks-at-the-media-briefingon-covid-19-11-march-2020. Accessed March 13, 2020. 
3. He F, Deng Y and Li W: Coronavirus Disease 2019 (COVID-19): What we know? J Med Virol 92: 719-725, 2020.

4. de Wit E, van Doremalen N, Falzarano D and Munster VJ: SARS and MERS: Recent insights into emerging coronaviruses. Nat Rev Microbiol 8: 523-534, 2016.

5. Chan JF, Yuan S, Kok KH, To KK, Chu H, Yang J, Xing F, Liu J, Yip CC, Poon RW, et al: A familial cluster of pneumonia associated with the 2019 novel coronavirus indicating person-to-person transmission: A study of a family cluster. Lancet 395: 514-523, 2020.

6. She J, Jiang J, Ye L, Hu L, Bai C and Song Y: 2019 novel coronavirus of pneumonia in Wuhan, China: Emerging attack and management strategies. Clin Transl Med 9: 19, 2020.

7. Zhang H, Penninger JM, Li Y, Zhong N and Slutsky AS: Angiotensin-converting enzyme 2 (ACE2) as a SARS-CoV-2 receptor: Molecular mechanisms and potential therapeutic target. Intensive Care Med 46: 586-590, 2020.

8. Zou L, Ruan F, Huang M, Liang L, Huang H, Hong Z, Yu J, Kang M, Song Y, Xia J, et al: SARS-CoV-2 viral load in upper respiratory specimens of infected patients. N Engl J Med 382: $1177-1179,2020$

9. Guo YR, Cao QD, Hong ZS, Tan YY, Chen SD, Jin HJ, Tan KS Wang DY and Yan Y: The origin, transmission and clinical therapies on coronavirus disease 2019 (COVID-19) outbreak-an update on the status. Mil Med Res 7: 11, 2020.

10. Zhou P, Yang XL, Wang XG, Hu B, Zhang L, Zhang W, Si HR Zhu Y, Li B, Huang CL, et al: A pneumonia outbreak associated with a new coronavirus of probable bat origin. Nature 579: 270-273, 2020

11. Ji Y, Ma Z, Peppelenbosch MP and Pan Q: Potential association between COVID-19 mortality and health-care resource availability. Lancet Glob Health 8: e480, 2020.

12. Sepkowitz KA and Eisenberg L: Occupational deaths among healthcare workers. Emerg Infect Dis 11: 1003-1008, 2005.

13. Integrated Surveillance of COVID-19 in Italy (Ordinanza $n$ 640 del 27/02/2020) 25 May 2020 update. Available from: https://www.epicentro.iss.it/en/coronavirus/bollettino/Infografica_ 25maggio\%20ENG.pdf. Accessed May 26, 2020.

14. Zhang S, Diao MY, Yu W, Pei L, Lin Z and Chen D: Estimation of the reproductive number of novel coronavirus (COVID-19) and the probable outbreak size on the Diamond Princess cruise ship: A data-driven analysis. Int J Infect Dis 93: 201-204, 2020.

15. D'arienzo M and Coniglio A: Assessment of the SARS-CoV-2 basic reproduction number, $\mathrm{R}_{0}$, based on the early phase of COVID-19 outbreak in Italy. Biosaf Health 2: 57-59, 2020.

16. Pomara C, Li Volti G and Cappello F: COVID-19 deaths: Are we sure it is pneumonia? Please, autopsy, autopsy, autopsy! J Clin Med 9, 1259, 2020.

17. Moher D, Liberati A, Tetzla J, Altman DG, Altman D, Antes G, Atkins D, Barbour V, Barrowman N, Berlin JA, et al: Preferred reporting items for systematic reviews and meta-analyses: The PRISMA statement. Ann Intern Med 151: 264-269, 2009.

18. Istituto Superiore di Sanità (ISS). Report 2020. Characteristics of COVID-19 patients dying in Italy. Available from: https://www. epicentro.iss.it/coronavirus/sars-cov-2-decessi-italia. Accessed May $15,2020$.

19. Chen N, Zhou M, Dong X, Qu J, Gong F, Han Y, Qiu Y, Wang J, Liu Y, Wei Y, et al: Epidemiological and clinical characteristics of 99 cases of 2019 novel coronavirus pneumonia in Wuhan, China: A descriptive study. Lancet 395: 507-513, 2020.

20. Guan WJ, Ni ZY, Hu Y, Liang WH, Ou CQ, He JX, Liu L, Shan H, Lei CL, Hui DSC, et al: Clinical characteristics of coronavirus disease 2019 in China. N Engl J Med 382: 1708-1720, 2020.

21. Zhou F, Yu T, Du R, Fan G, Liu Y, Liu Z, Xiang J, Wang Y, Song B, Gu X, et al: Clinical course and risk factors for mortality of adult inpatients with COVID-19 in Wuhan, China: A retrospective cohort study. Lancet 395: 1054-1062, 2020.

22. Shi S, Qin M, Shen B, Cai Y, Liu T, Yang F, Gong W, Liu X, Liang J, Zhao Q, et al: Association of cardiac injury with mortality in hospitalized patients with COVID-19 in Wuhan, China. JAMA Cardiol 25: 802-810, 2020.

23. Cao J, Tu WJ, Cheng W, Yu L, Liu YK, Hu X and Liu Q: Clinical features and short-term outcomes of 102 patients with coronavirus disease 2019 in Wuhan, China. Clin Infect Dis 71: 748-755, 2020.

24. Huang C, Wang Y, Li X, Ren L, Zhao J, Hu Y, Zhang L, Fan G, Xu J, Gu X, et al: Clinical features of patients infected with 2019 novel coronavirus in Wuhan, China. Lancet 395: 497-506, 2020.

25. Wang D, Hu B, Hu C, Zhu F, Liu X, Zhang J, Wang B, Xiang H, Cheng Z, Xiong Y, et al: Clinical characteristics of 138 hospitalized patients with 2019 novel coronavirus-infected pneumonia in Wuhan, China. JAMA 323: 1061-1069, 2020
26. Chen T, Wu D, Chen H, Yan W, Yang D, Chen G, Ma K, Xu D, Yu H, Wang $\mathrm{H}$, et al: Clinical characteristics of 113 deceased patients with coronavirus disease 2019: Retrospective study. BMJ 368: m1091, 2020

27. Wang Z, Yang B, Li Q, Wen L and Zhang R: Clinical features of 69 cases with coronavirus disease 2019 in Wuhan, China. Clin Infect Dis 71: 769-777, 2020.

28. Yang X, Yu Y, Xu J, Shu H, Xia J, Liu H, Wu Y, Zhang L, Yu Z, Fang M, et al: Clinical course and outcomes of critically ill patients with SARS-CoV-2 pneumonia in Wuhan, China: A single-centered, retrospective, observational study. Lancet Respir Med 8: 475-481, 2020

29. Liu K, Chen Y, Lin R and Han K: Clinical features of COVID-19 in elderly patients: A comparison with young and middle-aged patients. J Infect 80: e14-e18, 2020.

30. Ruan Q, Yang K, Wang W, Jiang L and Song J: Clinical predictors of mortality due to COVID-19 based on an analysis of data of 150 patients from Wuhan, China. Intensive Care Med 46: 846-848, 2020

31. Fauci AS, Lane HC and Redfield RR: Covid-19-navigating the uncharted. N Engl J Med 382: 1268-1269, 2020.

32. World Health Organization. Coronavirus disease (COVID-2019) situation reports 116. 2020. Available from: https://www.who. int/emergencies/diseases/novel-coronavirus-2019/situationreports. Accessed May 15, 2020.

33. Ceylan Z: Estimation of COVID-19 prevalence in Italy, Spain, and France. Sci Total Environ 729: 138817, 2020.

34. De Natale G, Ricciardi V, De Luca G, De Natale D, Di Meglio G, Ferragamo A, Marchitelli V, Piccolo A, Scala A, Somma R, et al: The COVID-19 infection in Italy: A statistical study of an abnormally severe disease. J Clin Med 9: 1564, 2020.

35. The Novel Coronavirus Pneumonia Emergency Response Epidemiology Team. The epidemiological characteristics of an outbreak of 2019 novel coronavirus diseases (COVID-19)-China, 2000. China CDC Weekly 2: 113-122, 2020.

36. Cagnacci A and Xholli A: Age-related difference in the rate of COVID-19 mortality in women versus men. Am J Obstet Gynecol 223: 453-454, 2020

37. Wenham C, Smith J and Morgan R; Gender and COVID-19 Working Group: COVID-19: The gendered impacts of the outbreak. Lancet 395: 846-848, 2020.

38. Channappanavar R, Fett C, Mack M, Ten Eyck PP, Meyerholz DK and Perlman S: Sex-based differences in susceptibility to severe acute respiratory syndrome coronavirus infection. J Immunol 198: 4046-4053, 2017.

39. Li X, Xu S, Yu M, Wang K, Tao Y, Zhou Y, Shi J, Zhou M, Wu B, Yang Z, et al: Risk factors for severity and mortality in adult COVID-19 inpatients in Wuhan. J Allergy Clin Immunol 146: $110-118,2020$

40. Zhou P, Huang Z, Xiao Y, Huang X and Fan XG: Protecting Chinese healthcare workers while combating the 2019 novel coronavirus. Infect Control Hosp Epidemiol 41: 745-746, 2020.

41. Li B, Yang J, Zhao F, Zhi L, Wang X, Liu L, Bi Z and Zhao Y: Prevalence and impact of cardiovascular metabolic diseases on COVID-19 in China. Clin Res Cardiol 109: 531-538, 2020.

42. Zheng YY, Ma YT, Zhang JY and Xie X: COVID-19 and the cardiovascular system. Nat Rev Cardiol 17: 259-260, 2020.

43. Bansal M: Cardiovascular disease and COVID-19. Diabetes. Metab Syndr 3: 247-250, 2020.

44. Cannizzaro E, Cirrincione L, Mazzucco W, Scorciapino A, Catalano C, Ramaci T, Ledda C and Plescia F: Night-time shift work and related stress responses: A study on security guards. Int J Environ Res Public Health 17: 562, 2020.

45. Occupational Safety \& Health Administration (OSHA). Guidance on preparing Workplaces for Covid-19. Available from: www. osha.gov/Publications/OSHA3990.pdf. Accessed May 15, 2020.

46. Cannizzaro E, Cannizzaro C, Martorana D, Moscadini S and Lo Coco D: Effects of shift work on cardiovascular activity, serum cortisol and white blood cell count in a group of italian fishermen. Euro Med Biomed J 2012: 109-113, 2012.

47. Rapisarda V, Nunnari G, Senia P, Vella F, Vitale E, Murabito P, Salerno $M$ and Ledda C: Hepatitis B vaccination coverage among medical residents from Catania University Hospital, Italy. Future Microbiol 14: 41-44, 2019.

48. Ledda C, Cinà D, Garozzo SF, Senia $\mathrm{P}$, Consoli $\mathrm{A}$, Marconi A, Scialfa V,Nunnari G and Rapisarda V: Tuberculosis screening among healthcare workers in Sicily, Italy. Future Microbiol 14: 37-40, 2019.

49. Modenese A and Gobba F: Increased risk of COVID-19-related deaths among general practitioners in Italy. Healthcare (Basel) 8: $155,2020$. 
50. Ramaci T, Barattucci M, Ledda C and Rapisarda V: Social stigma during COVID-19 and its impact on HCWs outcomes. Sustainability 12: 3834, 2020.

51. Ramaci T, Rapisarda V, Bellini D, Mucci N, De Giorgio A and Barattucci M: Mindfulness as a protective factor for dissatisfaction in HCWs: The moderating role of mindful attention between climate stress and job satisfaction. Int J Environ Res Public Health 17: 3818, 2020.

52. The Novel Coronavirus Pneumonia Emergency Response Epidemiology Team, Chinese center for disease control and prevention. The epidemiological characteristics of an outbreak of 2019 novel coronavirus diseases (COVID-19) in China. Chin J Epidemiol 42: 145-151, 2020

53. Conference on COVID-19, by Zeng Yixin, vice minister of China's National Health Commission. 1,700+ health care workers have the new coronavirus. https://www.advisory.com/dailybriefing/2020/02/14/coronavirus. Accessed March 28, 2020.

54. Rapisarda V, Ledda C and Maltezou HC: Vaccination in healthcare workers: Risk assessment, planning, strategy of intervention and legal implications. Future Microbiol 14: 1-3, 2019.

55. Heinzerling A, Stuckey MJ, Scheuer T, Xu K, Perkins KM, Resseger H, Magill S, Verani JR, Jain S, Acosta M and Epson E: Transmission of COVID-19 to health care personnel during exposures to a hospitalized patient-Solano County, California, February 2020. MMWR Morb Mortal Wkly Rep 69: 472-476, 2020.

56. Lai TH, Tang EW, Chau SK, Fung KS and Li KK: Stepping up infection control measures in ophthalmology during the novel coronavirus outbreak: An experience from Hong Kong. Graefes Arch Clin Exp Ophthalmol 8: 1049-1055, 2020.

57. Lu CW, Liu XF and Jia ZF: 2019-nCoV transmission through the ocular surface must not be ignored. Lancet 395: e39, 2020.

58. Tran K, Cimon K, Severn M, Pessoa-Silva CL and Conly J: Aerosol generating procedures and risk of transmission of acute respiratory infections to healthcare workers: A systematic review. PLoS One 7: e35797, 2012.

59. Ghinai I, McPherson TD, Hunter JC, Kirking HL, Christiansen D Joshi K, Rubin R, Morales-Estrada S, Black SR, Pacilli M, et al: First known person-to-person transmission of severe acute respiratory syndrome coronavirus 2 (SARS-CoV-2) in the USA. Lancet 395: 1137-1144, 2020.

60. Cai SJ, Wu LL, Chen DF, Li YX, Liu YJ, Fan YQ, Du SH, Huang H, Liu N, Cheng LL, et al: Analysis of bronchoscope-guided tracheal intubation in 12 cases with coronavirus disease 2019 under the personal protective equipment with positive pressure protective hood. Zhonghua Jie He He Hu Xi Za Zhi 43: 332-334, 2020 (In Chinese).

61. Center for disease Control and prevention. Available from: www. cdc.gov.it. Accessed May 15, 2020.

62. Istituto nazionale Assicurazione Infortuni sul Lavoro (INAIL) Scheda tecnica INAIL. I dati sulle denunce da Covid. Available from: www.inail.it. Accessed May 15, 2020.

63. Center for disease control and prevention (CDC). 2019 Novel Coronavirus, Wuhan,China.2020. Available from: https://www.cdc gov/coronavirus/2019-nCoV/summary.html. Accessed February 1, 2020.

64. Tsatsakis A, Calina D, Falzone L, Petrakis D, Mitrut R, Siokas V, Pennisi M, Lanza G, Libra M, Doukas SG, et al: SARS-CoV-2 pathophysiology and its clinical implications: An integrative overview of the pharmacotherapeutic management of COVID-19. Food Chem Toxicol 146: 111769, 2020.

65. Pennisi M, Lanza G, Falzone L, Fisicaro F, Ferri R and Bella R: SARS-CoV-2 and the nervous system: From clinical features to molecular mechanisms. Int J Mol Sci 21: 5475, 2020.

66. Kordzadeh-Kermani E, Khalili $\mathrm{H}$ and Karimzadeh I: Pathogenesis, clinical manifestations and complications of coronavirus disease 2019 (COVID-19). Future Microbiol 15 1287-1305, 2020.

67. Wang W, Tang J and Wei F: Updated understanding of the outbreak of 2019 novel coronavirus (2019-nCoV) in Wuhan, China. J Med Virol 92: 441-447, 2020.

68. Zhang JJ, Dong X, Cao YY, Yuan YD, Yang YB, Yan YQ Akdis CA and Gao YD: Clinical characteristics of 140 patients infected with SARS-CoV-2 in Wuhan, China. Allergy 75 : $1730-1741,2020$.

69. Adhikari SP, Meng S, Wu YJ, Mao YP, Ye RX, Wang QZ, Sun C, Sylvia S, Rozelle S, Raat H and Zhou H: Epidemiology, causes, clinical manifestation and diagnosis, prevention and control of coronavirus disease (COVID-19) during the early outbreak period: A scoping review. Infect Dis Poverty 9: 29, 2020.
70. Shi Y, Wang Y, Shao C, Huang J, Gan J, Huang X, Bucci E, Piacentini M, Ippolito G and Melino G: COVID-19 infection: The perspectives on immune responses. Cell Death Differ 27: 1451-1454, 2020

71. Zhu N, Zhang D, Wang W, Li X, Yang B, Song J, Zhao X, Huan B, Shi W, Lu R, et al: A novel coronavirus from patients with pneumonia in China, 2019. N Engl J Med 382: 727-733, 2020.

72. Costela-Ruiz VJ, Illescas-Montes R, Puerta-Puerta JM, Ruiz C and Melguizo-Rodríguez L: SARS-CoV-2 infection: The role of cytokines in COVID-19 disease. Cytokine Growth Factor Rev 54: 62-75, 2020

73. Rothan HA and Byrareddy SN: The epidemiology and pathogenesis of coronavirus disease (COVID-19) outbreak. J Autoimmun 109: 102433, 2020.

74. Bonetti G, Manelli F, Patroni A, Bettinardi A, Borrelli G, Fiordalisi G, Marino A, Menolfi A, Saggini S, Volpi R, et al: Laboratory predictors of death from coronavirus disease 2019 (COVID-19) in the area of Valcamonica, Italy. Clin Chem Lab Med 58: 1100-1105, 2020

75. Liu WJ, Zhao M, Liu K, Xu K, Wong G, Tan W and Gao GF: T-cell immunity of SARS-CoV: Implications for vaccine development against MERS-CoV. Antiviral Res 137: 82-92, 2017.

76. Vardavas C and Nikitara K: COVID-19 and smoking: A systematic review of the evidence. Tob Induc Dis 18: 20, 2020.

77. Zhao Y, Cui C, Zhang K, Liu J, Xu J, Nisenbaum E, Huang Y, Qin G, Chen B, Hoffer M, et al: COVID19: A systematic approach to early identification and healthcare worker protection. Front Public Health 8: 205, 2020.

78. Gao HN, Lu HZ, Cao B, Du B, Shang H, Gan JH, Lu SH, Yang YD, Fang Q, Shen YZ, et al: Clinical findings in 111 cases of influenza A (H7N9) virus infection. N Engl J Med 368: 2277-2285, 2013

79. Yang JK, Feng Y, Yuan MY, Yuan SY, Fu HJ, Wu BY, Sun GZ Yang GR, Zhang XL, Wang L, et al: Plasma glucose levels and diabetes are independent predictors for mortality and morbidity in patients with SARS. Diabet Med 23: 623-628, 2006.

80. Badawi A and Ryoo SG: Prevalence of comorbidities in the Middle East respiratory syndrome coronavirus (MERS-CoV): A systematic review and meta-analysis. Int J Infect Dis 49: 129-133, 2016.

81. Jaillon S, Berthenet K and Garlanda C: Sexual dimorphism in innate immunity. Clin Rev Allergy Immunol 56: 308-321, 2019.

82. Istituto Superiore di Sanitá (ISS). Epidemia COVID-19. Aggiornamento nazionale. Available from: https://www. epicentro.iss.it/coronavirus/bollettino/Bollettino-sorveglianzaintegrata-COVID-19_26-marzo\%202020.pdf. Accessed March $28,2020$.

83. Chen C, Zhou Y and Wang DW: SARS-CoV-2: A potential novel etiology of fulminant myocarditis. Herz 45: 230-232, 2020.

84. Blackburn R, Zhao H, Pebody R, Hayward A and Warren-Gash C: Laboratory-confirmed respiratory infections as predictors of hospital admission for myocardial infarction and stroke: Time-series analysis of English data for 2004-2015. Clin Infect Dis 67: 8-17, 2018

85. Magro C, Mulvey JJ, Berlin D, Nuovo G, Salvatore S, Harp J, Baxter-Stoltzfus A and Laurence J: Complement associated microvascular injury and thrombosis in the pathogenesis of severe COVID-19 infection: A report of five cases. Transl Res 220: 1-13, 2020.

86. Oudkerk M, Büller HR, Kuijpers D, van Es N, Oudkerk SF, McLoud TC, Gommers D, van Dissel J, Ten Cate H and van Beek EJR: Diagnosis, prevention, and treatment of thromboembolic complications in COVID-19: Report of the national institute for public health of the Netherlands. Radiology 297: E216-E222, 2020.

87. Han H, Yang L, Liu R, Liu F, Wu KL, Li J, Liu XH and Zhu CL: Prominent changes in blood coagulation of patients with SARS-CoV-2 infection. Clin Chem Lab Med 58: 1116-1120, 2020.

88. Tang N, Li D, Wang X and Sun Z: Abnormal coagulation parameters are associated with poor prognosis in patients with novel coronavirus pneumonia. J Thromb Haemost 18: 844-847, 2020.

89. Cheng Y, Luo R, Wang K, Zhang M, Wang Z, Dong L, Li J, Yao Y, Ge S and Xu G: Kidney disease is associated with in-hospital death of patients with COVID-19. Kidney Int 97: 829-838, 2020.

90. Naicker S, Yang CW, Hwangm SJ, Liu BC, Chen JH and Jha V: The novel coronavirus 2019 epidemic and kidneys. Kidney Int 97: 824-828, 2020

91. Durvasula R, Wellington T, McNamara E and Watnick S: COVID-19 and kidney failure in the acute care setting: Our experience from seattle. Am J Kidney Dis 76: 4-6, 2020. 
92.Zhang C, Wu Z, Li JW, Zhao $\mathrm{H}$ and Wang GQ: Cytokine release syndrome in severe COVID-19: Interleukin-6 receptor antagonist tocilizumab may be the key to reduce mortality. Int J Antimicrob Agents 55: 105954, 2020.

93. Tay MZ, Poh CM, Rénia L, MacAry PA and Ng LFP: The trinity of COVID-19: Immunity, inflammation and intervention. Nat Rev Immunol 20: 363-374, 2020. Luo P, Liu Y, Qiu L, Liu X, Liu D and Li J: Tocilizumab treatment in COVID-19: A single center experience. J Med Virol 92: 814-818, 2020.

94. Kooistra EJ, Waalders NJB, Grondman I, Janssen NAF, de Nooijer AH, Netea MG, van de Veerdonk FL, Ewalds E, van der Hoeven JG, Kox M, et al: Anakinra treatment in critically ill COVID-19 patients: A prospective cohort study. Crit Care 24 688,2020

95. Ucciferri C, Auricchio A, Di Nicola M, Potere N, Abbate A, Cipollone F, Vecchiet $\mathbf{J}$ and Falasca $\mathrm{K}$ : Canakinumab in a subgroup of patients with COVID-19. Lancet Rheumatol 2: e457-ee458, 2020.

96. Falzone L, Musso N, Gattuso G, Bongiorno D, Palermo CI, Scalia G, Libra M and Stefani S: Sensitivity assessment of droplet digital PCR for SARS-CoV-2 detection. Int J Mol Med 46: 957-964, 2020.

97. Knudsen L and Ochs M: The micromechanics of lung alveoli: Structure and function of surfactant and tissue components. Histochem Cell Biol 150: 661-676, 2018

98. Leiva-Juárez MM, Kolls JK and Evans SE: Lung epithelial cells: Therapeutically inducible effectors of antimicrobial defense. Mucosal Immunol 11: 21-34, 2018.

99. Liu Q, Wang RS, Qu GQ, Wang YY, Liu P, Zhu YZ, Fei G, Ren L, Zhou YW and Liu L: Gross examination report of a COVID-19 death autopsy. Fa Yi Xue Za Zhi 36: 21-23, 2020 (In English, Chinese).

100. Vella F, Senia P, Ceccarelli M, Vitale E, Maltezou H, Taibi R, Lleshi A, Venanzi Rullo E, Pellicanò GF, Rapisarda V, et al: Transmission mode associated with coronavirus disease 2019: A review. Eur Rev Med Farmacol Sci 24: 7889-7904, 2020.

101. World Health Organization (WHO). Coronavirus disease 2019 (COVID-19). Situation report 116. Available from: www.who.int/ emergencies/diseases/novel-coronavirus-2019/situation-reports. Accessed May 15, 2020

102. Center for Disease Control and Prevention (CDC). A weekly surveillance summery of U.S. Covid-19 activity. Available from https://www.cdc.gov/coronavirus/2019-ncov/covid-data/pdf/covidview-05-15-2020.pdf. Accessed May 18, 2020.

103. Centro Studi Politica Internazionale (CESPI). Covid-19. Diario settimanale sulla situazione nel mondo. Available from: www. cespi.com. Accessed May 15, 2020

104. Ramaci T, Barattucci M, Vella F, Senia P, Cannizzaro E, Scorciapino A, Ledda C, De Giorgio A and Rapisarda V: Straining at work and its relationship with personality profiles and individual consequences in healthcare workers (HCWs). Int J Environ Res Public Health 17: 610, 2020.

105. Bahl P, Doolan C, de Silva C, Chughtai AA, Bourouiba L and MacIntyre CR: Airborne or droplet precautions for health workers treating COVID-19? J Infect Dis: Apr 16, 2020 (Epub ahead of print). doi: 10.1093/infdis/jiaa189.

106. Istituto Superiore di Sanità (ISS). Integrated surveillance of COVID-19 in Italy. Available from: https://www.epicentro.iss. it/en/coronavirus/bollettino/Infografica_17aprile\%20ENG.pdf. Accessed May 15, 2020.

107. Kamerow D: Covid-19: Don't forget the impact on US family physicians. BMJ 368: $\mathrm{m} 1260,2020$.

108. Cirrincione L, Plescia F, Ledda C, Rapisarda V, Martorana D, Moldovan RE, Theodoridou K and Cannizzaro E: COVID-19 pandemic: Prevention and protection measures to be adopted at the workplace. Sustainability 12: 3603, 2020.
109. Nacoti M, Ciocca A, Giupponi A, Brambillasca P, Lussana F, Pisano M, Goisis G, Bonacina D, Fazzi F, Naspro R, et al: At the epicenter of the Covid-19 pandemic and humanitarian crises in Italy: Changing perspectives on preparation and mitigation. NEJM Catal: Mar 21, 2021 (Epub ahead of print). doi: $10.1056 /$ cat 20.0080

110. Chou R, Dana T, Buckley DI, Selph S, Fu R and Totten AM: Epidemiology of and risk factors for coronavirus infection in health care workers: A living rapid review. Ann Intern Med 173: 120-136, 2020.

111. Coronavirus disease 2019 (COVID-19) pandemic: Increased transmission in the EU/EEA and the UK-seventh update. Available from: www.ecdc.europa.eu. Accessed March 25, 2020.

112. Li W, Yang Y, Liu ZH, Zhao YL, Zhang Q, Zhang L, Cheung T and Xiang YT: Progression of mental health services during the COVID-19 outbreak in China. Int J Biol Sci 16: 1732-1738, 2020

113. Augustine R, Das S, Hasan A, S A, Abdul Salam S, Augustine P, Dalvi YB, Varghese R, Primavera R, Yassine HM, et al: Rapid antibody-based COVID-19 mass surveillance: Relevance, challenges, and prospects in a pandemic and post-pandemic world. J Clin Med 9: 3372, 2020.

114. Skoll D, Miller JC and Saxon LA: COVID-19 testing and infection surveillance: Is a combined digital contact-tracing and mass-testing solution feasible in the United States? Cardiovasc Digit Health J 1: 149-159, 2020.

115. Ucciferri C, Vecchiet J and Falasca K: Role of monoclonal antibody drugs in the treatment of COVID-19. World J Clin Cases 8: 4280-4285, 2020.

116. Rotzinger DC, Beigelman-Aubry C, von Garnier C and Qanadli SD: Pulmonary embolism in patients with COVID-19: Time to change the paradigm of computed tomography. Thromb Res 190: 58-59, 2020.

117. Marrie TJ and Shariatzadeh MR: Community-acquired pneumonia requiring admission to an intensive care unit: A descriptive study. Medicine (Baltimore) 86: 103-111, 2007.

118. Thachil J, Tang N, Gando S, Falanga A, Cattaneo M, Levi M, Clark $\mathrm{C}$ and Iba T: ISTH interim guidance on recognition and management of coagulopathy in COVID-19. J Thromb Haemost 18: 1023-1026, 2020.

119. Italian National Statistics Institute (ISTAT). Report February 13. Available from: www.istat.it. Accessed April 20, 2020.

120. Baud D, Qi X, Nielsen-Saines K, Musso D, Pomar L and Favre G: Real estimates of mortality following COVID-19 infection. Lancet Infect Dis 20: 773, 2020.

121. Salerno M, Sessa F, Piscopo A, Montana A, Torrisi M, Patanè F, Murabito P, Volti GL and Pomara C: No autopsies on COVID-19 deaths: A missed opportunity and the lockdown of science. J Clin Med 9: 1472, 2020.

122. Barth RF, Xu X and Buja LM: A call to action: The need for autopsies to determine the full extent of organ involvement associated with COVID-19. Chest 158: 43-44, 2020.

123. Costantino C, Cannizzaro E, Alba D, Conforto A, Cimino L and Mazzucco W: SARS-CoV-2 pandemic in the mediterranean area: Epidemiology and perspectives. EuroMediterranean Biomed J 15: 102-106, 2020.

124. Costantino C, Ledda C, Genovese C, Contrino E, Vitale E, Maida CM, Squeri R, Vitale F and Rapisarda V: Immunization status against measles of health-care workers operating at three sicilian university hospitals: An observational study. Vaccines (Basel) 7: 175, 2019

125. Yamaoka-Tojo M: Endothelial glycocalyx damage as a systemic inflammatory microvascular endotheliopathy in COVID-19. Biomed J 43: 399-413, 2020.

126. Hunter DJ: Covid-19 and the stiff upper lip-the pandemic response in the United Kingdom. N Engl J Med 382: e31, 2020. 